\title{
Produção de exopolissacarídeos pela cianobactéria Nostoc sp em dife- rentes concentrações de nitrogênio e glicose
}

\author{
Exopolysaccharide production by the cyanobacteria Nostoc $s p$ in \\ different concentrations of nitrogen and glucose
}

\author{
Liege A. Kawai ${ }^{1}$; Maria Helena P. Pinotti²; Maria Antonia P. C. Celligoi ${ }^{3}$
}

\section{Resumo}

Cianobactérias são microrganismos procariontes que, durante o crescimento celular, são capazes de produzir exopolissacarídeos (EPS). Devido à diversidade bioquímica destes, podem ser excelentes para vários fins biotecnológicos, tendo aplicações em indústrias alimentícias, têxteis, de tintas, cosméticos, de papel, e farmacêuticas, como floculantes, espessantes ou estabilizadores, substituindo os polissacarídeos de macroalgas e plantas. Além disso, as cianobactérias apresentam taxas maiores de crescimento e são mais fáceis de manipular do que plantas e macroalgas. Este estudo teve por objetivo otimizar a produção de EPS no meio BG11, com relação a diferentes concentrações de nitrogênio e glicose do meio de cultivo na produção de EPS e biomassa pela cianobactéria Nostoc sp.

Palavras-chave: Exopolissacarídeo. Cianobactéria. Nostoc sp.

\begin{abstract}
Cyanobacteria are prokaryotic microorganisms that can produce exopolysaccharide (EPS) during their cellular growth and due to their biochemical diversity, they can be considered as excellent in various biotechnological applications, being used in food, textile, ink, cosmetics, paper and pharmaceutical industries as gelling, flocculants or emulsifier agents, substituting the polysaccharides of macroalgae and plants. Besides, microorganisms present higher growth rates and they are easier to manipulate than plants and macroalgae. The objective of the present study is to optimize the EPS production in BG11 medium related to the different nitrogen and glucose concentrations in the culture for the EPS and biomass production by the cyanobacteria Nostoc sp.
\end{abstract}

Key words: Exopolysaccharide. Cyanobacteria. Nostoc $s p$.

\footnotetext{
${ }^{1}$ Aluna do Curso de Ciências Biológicas - Bolsista UEL de Iniciação Científica- Universidade Estadual de Londrina. E-mail: liege_kawai@yahoo.com

${ }^{2}$ Docente do Departamento de Bioquímica e Biotecnologia - CCE - Universidade Estadual de Londrina. E-mail: mhpinotti@sercomtel.com.br

${ }^{3}$ Docente do Departamento de Bioquímica e Biotecnologia - CCE - Universidade Estadual de Londrina.
} 


\section{Introdução}

Cianobactérias são procariontes fotoautotróficos que, sob algumas condições, podem crescer em condições mixotróficas, e, delas, algumas ainda podem apresentar crescimento heterotrófico no escuro (DE PHILIPPIS et al., 2001). Há uma grande variedade de espécies de cianobactérias bastante difundidas e com propriedades diversas em sua morfologia, fisiologia e bioquímica. Podem ser aquáticas ou terrestres, viver em ambientes extremos, tanto aqueles iluminados naturalmente como em substratos orgânicos com pouca luz. Algumas espécies podem sobreviver em condições anaeróbicas, tendo o sulfato como doador de elétrons para a fotossíntese (DE PHILIPPIS; VINCENZINI, 1998). Além disso, muitas espécies de cianobactérias são diazotróficas, ou seja, são capazes de usar nitrogênio atmosférico, portanto não necessitam de fontes de tal nutriente no meio de cultivo (MORENO et al., 1998).

Muitos cianobactérias secretam mucilagens, constituídas por exopolissacarídeos (EPS), durante seu crescimento celular e, devidoà diversidade bioquímica destes, possuem várias aplicações biotecnológicas, em indústrias alimentícias, têxteis, de tintas, cosméticos, de papel, e farmacêuticas, como emulsificantes, floculantes ou estabilizadores (DE PHILIPPIS; VINCENZINI, 1998; MORENO et al., 1998). Alguns EPS de cianobactérias têm aplicações biomédicas potenciais, como drogas anti-virais e antitumorais (HAYASHI et al., 1996; HIRAHASHI et al., 2002). O uso de EPS de cianobactérias é importante porque esses microrganismos apresentam maiores taxas de crescimento e são mais fáceis de manipular do que macroalgas e plantas superiores e por seus EPS possuírem propriedades físicas equímicas únicas (MORENO et al., 1998; OTERO; VICENZINI, 2003).

Apesar dos estudos dos EPS de cianobactérias terem-se iniciado nos meados do século passado, a grande maioria das pesquisas tem-se dedicado à identificação da sua estrutura química, de modo que foram feitos poucos estudos acerca da influência dos parâmetros nutricionais, físicos e químicos na síntese dos mesmos (DE PHILIPPIS et al., 2001). No entanto, a produção, quantidade e estrutura do EPS podem variar de uma espécie para outra, ou mesmo dentro da mesma espécie, dependendo das alterações nas variáveis ambientais e nutricionais do meio onde a cianobactéria cresce (MORENO et al., 1998).

Moreno et al. (1998) verificaram que a cianobactéria Anabaena sp ATCC 33047 não foi afetada quanto ao seu crescimento celular pela presença de nitrogênio combinado, porém, nesse caso, a produção de EPS decresceu. Otero e Vincenzini (2003) estudaram o efeito da disponibilidade de nitrogênio combinado na síntese de EPS, em três cepas de Nostoc sp (PCC7413, PCC736 e PCC8113), conhecidas por serem diazotróficas, porém com capacidade de crescimento em condições não-diazotróficas. Quando adequadamente aclimatadas à presença de nitrato, todas as cepas capsuladas testadas tornaram-se não-capsuladas, e nenhum EPS foi produzido. A cepa Nostoc PCC 7413 foi a única a liberar EPS em condições diazotróficas e nãodiazotróficas, com os valores mais altos sendo encontrados em presença de nitrato.

Andrade, Silva e Pinotti (2004) verificaram que, para Nostoc sp isolado em seu laboratório (MORIOKA, 2002), o aumento da concentração de nitrogênio no meio, em condições autotróficas, melhorou a produção de biomassa, porém não houve diferença significativa na produção de EPS. Quando um substrato orgânico, glicose, foi adicionado ao meio, a biomassa aumentou com $1,5 \mathrm{~g} /$ $\mathrm{L}$ de $\mathrm{NaNO}_{3}$, diminuindo quando se dobrava a quantidade de nitrogênio. No entanto, a produção de EPS foi maior sem suplementação de nitrogênio, não havendo diferença significativa em todos os outros tratamentos.

O presente estudo teve por objetivo otimizar a produção de EPS pela cianobactéria Nostoc sp com relação a diferentes concentrações de nitrogênio e glicose do meio de cultivo. 


\section{Material e Métodos}

\section{Microalga}

A cianobactéria Nostoc sp utilizada no estudo foi isolada no Laboratório de Bioquímica da Universidade Estadual de Londrina e, posteriormente, classificada pela Dr ${ }^{a}$ Célia Sant' Ana, do Instituto Botânico, São Paulo/ SP (MORIOKA, 2002).

\section{Condições de Cultivo}

Para a manutenção de cultura, foi utilizado o meio BG11 (STANIER et al., 1971). No experimento, foi preparado o meio BG11 sem bicarbonato $\left(\mathrm{Na}_{2} \mathrm{CO}_{3}\right)$ e sem $\mathrm{NaNO}_{3}$, sendo este suplementado com glicose

A concentração de EPS variou de $0,048 \mathrm{~g} / \mathrm{L}$ a $0,361 \mathrm{~g} / \mathrm{L}$ nas diferentes condições testadas. Para produção de EPS, obteve-se a equação:

$$
\mathrm{Y}=0,156+0,2205 \mathrm{x}_{1}-0,0475 \mathrm{x}_{2}
$$

Tabela 1. Suplementação do meio BG11 com glicose e $\mathrm{NaNO}_{3}$.

\begin{tabular}{ccc}
\hline Ensaios & Glicose $\mathbf{g} / \mathbf{L}$ & $\mathrm{NaNO}_{3} \mathbf{g} / \mathbf{L}$ \\
\hline $1,2,3$ & 1,5 & 1,0 \\
$4,5,6$ & 2,5 & 1,0 \\
$7,8,9$ & 1,5 & 2,0 \\
$10,11,12$ & 2,5 & 2,0 \\
$13,14,15$ & 2,0 & 1,5 \\
\hline
\end{tabular}

Os cultivos foram feitos em Erlenmeyers de 250 $\mathrm{mL}$ contendo $50 \mathrm{~mL}$ de meio, durante 21 dias, em um agitador rotatório com temperatura constante a $32^{\circ} \mathrm{C}+$ ou $-2^{\circ} \mathrm{C}$, com agitação de $120 \mathrm{rpm}$ e luminosidade de 600 lux, medida na superfície da cultura com um luxímetro digital.

\section{Obtenção de Biomassa e EPS}

A biomassa foi separada por centrifugação a $10000 \mathrm{x} \mathrm{g}$, por 20 minutos, em uma centrífuga refrigerada a $4^{\circ} \mathrm{C}$. O sobrenadante de cada cultivo, contendo o EPS, foi reservado para dosagem de açúcar total pelo método Fenol - Sulfúrico (DUBOIS et al, 1956) e açúcar redutor pelo método Somogyi Nelson (NELSON, 1944), enquanto a biomassa foi ressuspensa em $10 \mathrm{~mL}$ de água deionizada.

\section{Determinação da biomassa}

A determinação da biomassa foi feita por gravimetria: $1 \mathrm{~mL}$ de suspensão de biomassa foi colocada em cadinho previamente deixado na estufa durante $24 \mathrm{~h}$ e pesado. $\mathrm{O}$ cadinho com a biomassa foi colocado em estufa a $70^{\circ} \mathrm{C}$ até peso constante. A biomassa foi determinada em triplicata.

\section{Planejamento Estatístico}

Os experimentos foram realizados segundo os princípios da metodologia estatística da superfície de resposta, tendo como variáveis independentes a concentração de glicose e a concentração de $\mathrm{NaNO}_{3}$, representadas por $\mathrm{x}_{1}$ e $\mathrm{x}_{2}$, respectivamente. Os níveis de variação utilizados foram 1,5 e $2,5 \mathrm{~g} / \mathrm{L}$ de glicose e 1,0 e 2,0 g/L de $\mathrm{NaNO}_{3}$. Foi utilizado planejamento fatorial $2^{2}$, com três repetições no ponto central (BARROS NETO; SCARMINIO; BRUNS, 1995).

Duas respostas foram analisadas: produção de biomassa e produção de EPS.

\section{Resultados e Discussão}

Os resultados do experimento estão representados na Tabela 2. 
Tabela 2. Resultados do planejamento fatorial $2^{2}$ com ponto central. $\mathrm{x}_{1}$ e $\mathrm{x}_{2}$ representam os valores das variáveis codificadas pelas equações $\mathrm{x}_{1}=\left(\mathrm{C}_{\mathrm{N}}-1,5\right)$ e $\mathrm{x}_{2}=\left(\mathrm{C}_{\mathrm{gli}}-2,0\right)$.

\begin{tabular}{ccccccc}
\hline Ensaio & Glicose $\mathrm{g} / \mathrm{L}$ & $\mathrm{NaNO}_{3} \mathrm{~g} / \mathrm{L}$ & $\mathrm{x}_{1}$ & $\mathrm{x}_{2}$ & $\mathrm{EPS} \mathrm{mg} / \mathrm{L}$ & Biomassa $\mathrm{g} / \mathrm{L}$ \\
\hline 1 & 1,5 & 1,0 & -1 & -1 & 0,048 & 12,23 \\
2 & 2,5 & 1,0 & +1 & -1 & 0,361 & 14,43 \\
3 & 1,5 & 2,0 & -1 & +1 & 0,093 & 11,10 \\
4 & 2,5 & 2,0 & +1 & +1 & 0,221 & 11,10 \\
5 & 2,0 & 1,5 & 0 & 0 & 0,160 & 16,70 \\
6 & 2,0 & 1,5 & 0 & 0 & 0,103 & 13,30 \\
7 & 2,0 & 1,5 & 0 & 0 & 0,110 & 15,0 \\
\hline
\end{tabular}

A concentração de EPS variou de $0,048 \mathrm{~g} / \mathrm{L}$ a 0,361 g/L nas diferentes condições testadas. Para produção de EPS, obteve-se a equação:

$\mathrm{Y}=0,156+0,2205 \mathrm{x}_{1}-0,0475 \mathrm{x}_{2}$ $( \pm 0,0117) \quad( \pm 0,0155) \quad( \pm 0,0155)$
Segundo a análise estatística, não há evidência de falta de ajuste do modelo, portanto pode-se representar a superfície de resposta como um plano, mostrado na Figura 1. Há uma interação significativa entre as variáveis estudadas, sendo significativa a variável concentração de glicose.

A maior produção de EPS foi de $0,361 \mathrm{~g} / \mathrm{L}$ empregando-se 2,5 g/L de glicose e 1,0 g/L de $\mathrm{NaNO}_{3}$.
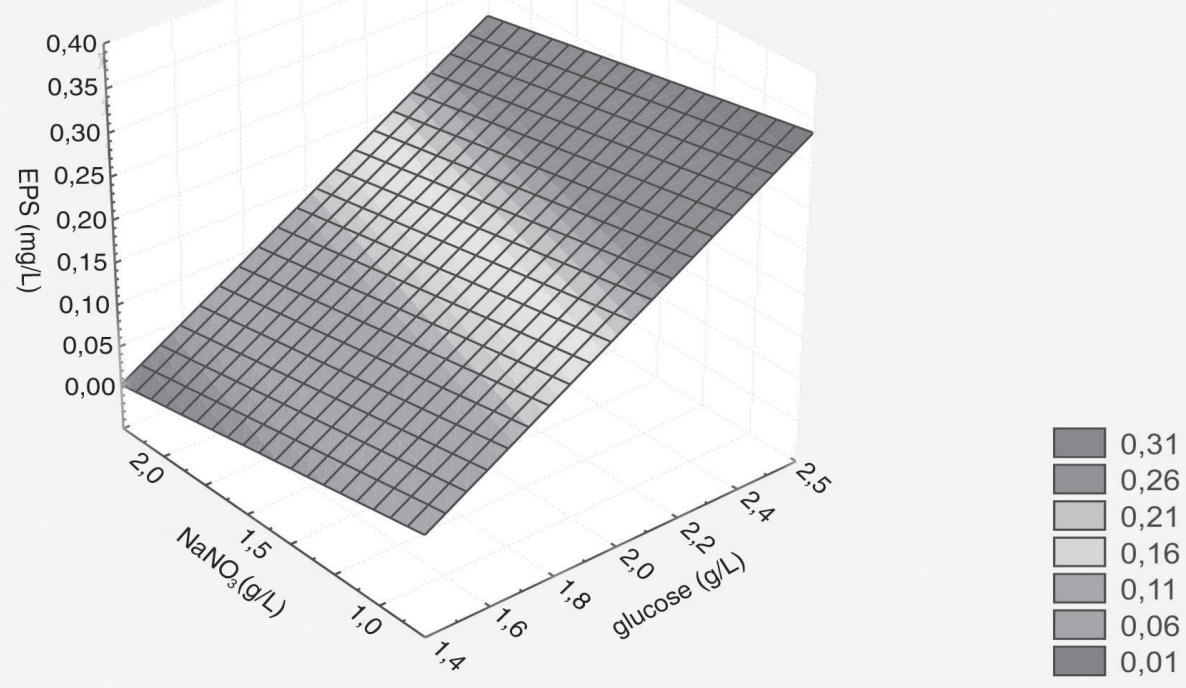

Figura 1. Superfície de resposta para a análise de EPS. 
Para a biomassa, a variação foi de $11,10 \mathrm{~g} / \mathrm{L}$ para $16,70 \mathrm{~g} / \mathrm{L}$, obtendo-se a seguinte equação:

$$
\begin{gathered}
Y=11,82+1,1 x_{1}-4,46 x_{2} \\
( \pm 0,981)( \pm 0,85)( \pm 0,85)
\end{gathered}
$$

Nesse caso, $\mathrm{o}$ efeito $\mathrm{x}_{1}$, de variar a concentração de glicose não foi significativo mas quando a concentração de nitrato é aumentada de 1,0 g/L para 2,0 g/L há uma diminuição na concentração de biomassa. Na realidade, a melhor produção de biomassa ocorrendo no ponto central, com $1,5 \mathrm{~g} / \mathrm{L}$ de nitrato e 2,0 g/L de glicose, o mesmo resultado obtido por Andrade, Silva e Pinotti (2005) com a mesma cianobactéria.
Acredita-se que a síntese de EPS representa uma estratégia metabólica para sobrevivência de cianobactérias em condições desfavoráveis (DE PHILIPPIS; VINCENZINI, 1998). Tem sido descrito que a falta de nitrogênio aumenta a síntese de EPS em cianobactérias (DE PHILIPPIS et al., 2001; MORENO et al., 1998). Quando se aumentou a concentração de nitrato de $1,0 \mathrm{~g} / \mathrm{L}$ para $1,5 \mathrm{~g} / \mathrm{L}$, houve um aumento da biomassa, porém uma diminuição da concentração de EPS. A diminuição da concentração de nitrogênio no meio favorece a produção de EPS quando a concentração de glicose é aumentada. Isso pode provavelmente ocorrer devido ao estresse da diminuição do nitrogênio aliado ao nível abundante de carbono fornecido pela glicose.

A Figura 2 mostra a superfície de resposta obtida para a produção de biomassa.

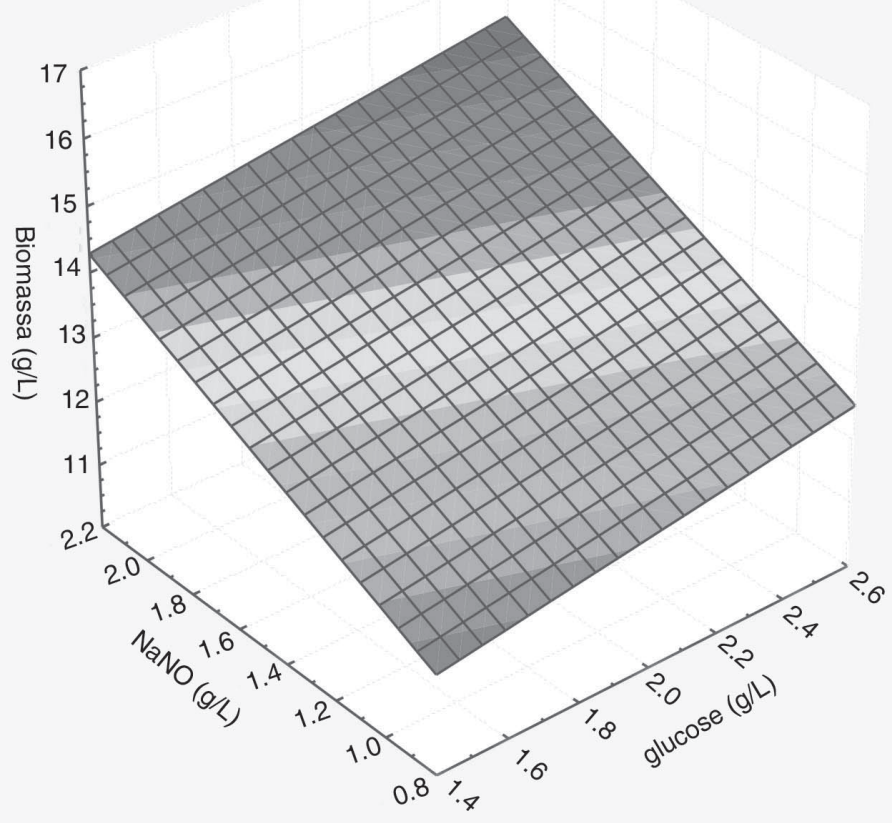




\section{Conclusão}

Foi obtido um aumento da concentração de EPS com o aumento da concentração de glicose no meio. A maior produção de EPS foi de $0,361 \mathrm{~g} / \mathrm{L}$ empregando-se 2,5 g/L de glicose e 1,0 g/L de $\mathrm{NaNO}_{3}$. No entanto, a produção de biomassa não acompanhou a produção de EPS, a maior produção ocorrendo com 1,5 g/L de nitrato e 2,0 g/L de glicose. Se a produção de biomassa não for importante, podem-se usar as primeiras condições citadas acima para direcionar para a produção de EPS.

No século passado, iniciaram-se estudos com EPS de cianobactérias, dedicados à identificação da sua estrutura, havendo poucos estudos sobre a influência dos parâmetros nutricionais, físicos e químicos na síntese dos mesmos. Atualmente, há trabalhos acerca da quantificação e produção de EPS, sempre visando à produção em larga escala. Mesmo com toda essa tecnologia e estudos, ainda há grandes lacunas a serem preenchidas, como otimização do meio de cultivo para tal produção e estudos sobre a aplicação e eficácia na utilização desses EPS. Essa área de pesquisa vem-se tornando ampla e promissora, com possíveis descobertas importantes tanto para aplicações na indústria biomédica, quanto nas indústrias alimentícias e têxteis, entre outras.

\section{Agradecimentos}

A Universidade Estadual de Londrina/PROPPG pela bolsa de iniciação científica concedida a aluna.

\section{Referências}

ANDRADE, E.; SILVA, M.; PINOTTI, M. H. P. Produção de exopolissacarídeos por Nostoc sp em cultivo autotrófico e mixotrófico, com diferentes concentrações de nitrogênio. In: SIMPÓSIO NACIONAL DE BIOPROCESSOS, 15., 2005, Recife. Anais... Recife: SINAFERM, 2005. CDROM.
BARROS NETO, B.; SCARMINIO, I. S.; BRUNS, R. E. Planejamento e otimização de experimentos. Campinas: Ed. UNICAMP, 1995.

CAMILIOS NETO, D.; PINOTTI, M. H. P. Exopolissacarídeos de cianobactérias. Semina: Ciências Exatas e Tecnológicas, Londrina, v.25, n.1, p.43-52, 2004.

DE PHILIPPIS, R.; SILI, C.; PAPERI, R.; VINCENZINI, M. Exopolysaccharide-producing cyanobacteria and their possible exploitation: A review. Journal of Applied Phycology, Dordrecht, v.13, n.4, p.293-299, aug. 2001.

DE PHILIPPIS, R.; VINCENZINI, M. Exocellular polysaccharides from cyanobacteria and their possible applications. FEMS Microbiology Reviews, Amsterdam, v.22, n.3, p.151-175, sep. 1998.

DUBOIS, M.; GILLES; K A; HAMILTON, J. K; REBERS, P.A; SMITH, F. Colorimetric methods for determination of sugars and related substances. Journal of Analytical Chemistry, Washington, v.28, n.3, p.350-356, 1956.

HAYASHI, T.; HAYASHI, K.; MAEDA, M.; KOJIMA, I. Calcium Spirulan, an inhibitor of enveloped virus replication, from a blue-green alga Spirulina platensis. Journal of Natural Products, Cincinnati, v.59, n.1, p.83-87, jan. 1996.

HIRAHASHI, T.; MATSUMOTO, M; HAZEKI, K.; SAEKI, Y.; UI, M. SEYA, T. Activation of the human innate immune system by Spirulina: augmentation of interferon production and NK cytotoxicity by oral administration of hot water extract of Spirulina platensis. International Immunopharmacology, Amsterdam, v.2, n.4, p.423-434, mar. 2002.

MORENO, J.; VARGAS, M. A; OLIVARES, H.; RIVAS, J.; GUERRERO, M. G. Exopolysaccharide production by the cyanobacterium Anabaena sp. ATCC 33047 in batch and continuous culture. Journal 
Produção de exopolissacarídeos pela cianobactéria Nostoc sp em diferentes concentrações de nitrogênio e glicose

of Biotechnology, Amsterdam, v.60, n.3, p.175-182, feb. 1998.

MORIOKA, I. R. L. Crescimento mixotrófico de Nostoc sp em sacarose e melaço de cana-de-açúcar para a produção de biomassa e ficobiliproteínas. 2002. Dissertação (Monografia de Bacharel)-Universidade Estadual de Londrina, Londrina.

NELSON, N. A photometric adaptation of the Somogyi method for determination of glucose. The Journal of Biological Chemistry, Bethesda, v.153, p.375-380, 1944.

OTERO, A; VICENZINI, M. Extracellular polysaccharide synthesis by Nostoc strains as affected by $\mathrm{N}$ source and light intensity. Journal of Biotechnology, Amsterdam, v.102, n.2, p.143-152, apr. 2003.

STANIER, R. Y.; KUNISAWA, R.; MANDEL, M; COHEN-BAZIRE, G. Purification and properties of unicellular blue-green algae (Order Chroococcales). Bacteriological Reviews, Baltimore, v.35, n.2, p.171205, 1971. 